\title{
Moisture content as a deteriorating factor for common building stones in London
}

\author{
Sudeshna Basu a,b,*, Yasemin D. Aktas ${ }^{\mathrm{c}, \mathrm{d}}$ \\ a.Department of Earth Sciences, University College London, 5 Gower Place, London WC1E 6BS, UK \\ b.Department of Chemical Engineering, University College London, Bloomsbury, London WC1E 7JE, UK \\ c.Department of Civil, Environmental and Geomatic Engineering, Kings Cross, London WC1E 6DE, UK; \\ d. UK Centre for Moisture in Buildings (UKCMB), London WC1H ONN, UK
}

\begin{abstract}
Moisture content and its distribution within the rock mass can affect its deterioration. This has not been considered in details in the context of their specific properties for the common building stones in London such as limestone, granite and marble. Based on an extensive literature survey on specific rock properties and observed surficial deterioration from this study, it is evident that deterioration can be correlated to moisture transport and retention. For example in limestone, it can be related to their sorption-behaviour in response to subtle changes in humidity, intrinsically controlled by their porosity and pore structure. In marble, surficial moisture condensation enhances deposition of airborne particles accelerating chemical and biological decay, influenced by grain size and interlocking.
\end{abstract}

Peer-review under the responsibility of the organizing committee of the ICMB21.

Keywords: Building stones, Relative humidity, Microcracking, Porosity, Surface decay

\section{Terminology}

Oolite Spherical grains composed of concentric layers, formed under shallow marine conditions due to the precipitation of calcium carbonate around the nucleus, the rounded morphology acquired due to the wave action.

Sparite $\quad$ Coarse $(>0.01 \mathrm{~mm})$ calcite crystals acting as the cementing material in limestone, precipitated from carbonate solutions.

Kaolinisation Alteration of minerals especially feldspar and mica to kaolinite (a clay mineral) due to weathering.

Sericitisation Alteration of plagioclase feldspar to sericite (fine grained phyllosilicate)

\section{Introduction}

Limestone, granite and marble are the three most common building stones in London [1]. Of all limestone, the Portland Stone, which is a well cemented oolitic limestone is most common and has been used in the construction of many important buildings including British Museum and University College London. Other limestone commonly used are Bath, Caen, Quarr and Purbeck Stones with variation in the degree of cementation, constituent particles present such as pellets, bioclasts, oolites and the degree and type of cementing material. The granite and the marble also show variation in mineralogy and texture being procured from different locations in UK and other countries. For example, the Royken granite used in the British Library has been sourced from Norway. But other varieties of granitic building stones from Cornwall and Aberdeen having different colour and texture are commonly used too. Of the marble, the famous Marble Arch is made of Carrara marble, but other types such as the Perlato Marble for the internal flooring of Euston station and the Connemara Marble used as paving stones in the Tottenham Court Road are also seen. The different types of marble are different from each other in terms of grain interlocking and sizes, orientation of certain minerals present such as clay minerals, presence of any impurities such as pyrite occurring along veins as well as calcite/dolomite ratio. Both marble and granite can be polished and protected from decay to an extent.

Most processes of stone deterioration including salt crystallization, biocolonisation, swelling and chemical weathering require the presence of water. Consequently, the availability of moisture can be critical in driving the deterioration of these building stones. Because it can be easily measured, relative humidity is often used as a transition index reflecting moisture content [2]. Depending 


\section{ICMB21}

on the relative humidity, the transport mechanism of the available water can be as vapour under low humidity conditions or, more efficiently via capillary condensation under higher relative humidity [3].

\section{Objectives of the study}

This study focuses on, how any change in relative humidity can affect the moisture content and subsequent deterioration of the three dominant building stones in the London, in the context of their mineralogy, fabric and petrophysical properties. Of the petrophysical properties, the effect of porosity has been emphasized on as it is particularly important in stone deterioration with a continuum from nanometers to millimetres sized pore spaces, forming an interconnected pore system in most of these stones. This study is particularly relevant considering that occurrences of low humidity is becoming more frequent, with a notable decline in the summer relative humidity since the 1920s [4].

\section{Methodology}

In this study different limestone, granite and marble used as building stones in London, particularly in and around University College London, from Tottenham Court Road to Euston Road (till St. Pancas International Station) were visually inspected for deterioration to identify any cracking, crumpling, flaking, scaling, crust formation and detachment. Beside colour, gloss and roughness were also used to assess surficial decay. The observed decay were correlated to the stone properties including mineralogy, texture and petrophysical properties based on a detailed literature survey, for a better understanding of the decay processes and impacts of relative humidity and moisture content.

\section{Results and discussion}

Although generally resistant, if the Portland Stone is already weathered, the added pore spaces can provide additional area for moisture retention accelerating further decay. In addition, the porosity associated with the pellets, oolites, bioclasts and the sparite cement can aid in moisture expansion, inducing mechanical stress as observed for the Caen and Bath Stones. In Purbeck Stone, the deterioration can occur due to clay mineral swelling that can be attributed to moisture condensation and delamination along the bedding planes. For marble, micro cracks formed as a consequence of differential heating and cooling, can act as pathways for moisture transport and retention. The moisture content controls marble degradation by bowing, with a retarded expansion when water is available. In granite, the presence of micro cracks and other points of weakness such as cleavage planes in feldspar and mica, act as pathways of moisture transport facilitating chemical decay via kaolinisation and sericitisation.

\section{Conclusions}

Although their relationship is likely to be non-linear, it is imperative that, relative humidity and consequently moisture content and its distribution in the rock mass, is closely related to the temperature, and as interlinked attributes have strong implications towards the pore water saturation and consequent building stone deterioration. Relative humidity also controls the deposition velocity of $\mathrm{SO}_{2}$ on building surfaces along with the deposition of nitrogen oxides and other particulate matter, that needs to be investigated further to predict how it can affect biological and chemical decay of these stones. Under the predicted wetter conditions for the future in UK and particularly London, the role of moisture dilatation may be considerably enhanced and requires further attention.

\section{References}

[1] Basu, S., Orr, S.A., \& Aktas, Y.D. (2020). A Geological Perspective on Climate Change and Building Stone Deterioration in London: Implications for Urban Stone-Built Heritage Research and Management. Atmosphere, 11(8), 788.

[2] Jiang, J., Yuan, Y. (2013). Relationship of moisture content with temperature and relative humidity in concrete. Magazine of Concrete Research, 65(11), 685692.

[3] Franzen, C., Mirwald, P.W. (2004). Moisture content of natural stone: Static and dynamic equilibrium with atmospheric humidity. Environmental Geology, 46, 391-401.

[4] London Climate Change Partnership. (2002). A Climate Change Impacts in London Evaluation Study.

* Correspondence: sudeshna.basu@ucl.ac.uk+44(0)7505209327 